The tables show that the radio-oleic-acid test is as useful in the diagnosis of steatorrhoea as the more traditional radiotriolein test. In addition it provides a valuable aid in the differential diagnosis of the cause of the steatorrhoea. The patients with idiopathic steatorrhoea (excluding the special case referred to above) excreted between 6 and $55 \%$ of the dose of radioactive oleic acid in the faeces. None of the four patients with pancreatic steatorrhoea excreted more than $7 \%$. The two that excreted 6 and $7 \%$ respectively were both in the late stages of the disease ; one had diabetes mellitus and the other calcification of the pancreas, and neither presented a diagnostic problem. The other two were early cases, and the involvement of the pancreas would have been overlooked if it had not been possible to intubate them and measure the pancreatic enzymes in the duodenal juice.

In the four patients-two with pancreatic steatorrhoea and two with idiopathic steatorrhoea-in whom both the radiotriolein test and the radio-oleic-acid test were performed (Table VI) the results were as expected. In the two with pancreatic steatorrhoea excretion of radioactivity in the faeces after the administration of radiotriolein was much greater than when radio-oleic acid was given. In contrast, the two patients with idiopathic steatorrhoea excreted $10-15 \%$ of the radiooleic acid, while the excretion of radiotriolein was much less than in the two patients with pancreatic involvement.

\section{Summary}

A reliable method for the administration of radiotriolein and radio-oleic acid is described.

In 12 normal subjects the faecal excretion of radiotriolein was $1 \%$ or less of the administered dose, whereas in seven patients with idiopathic steatorrhoea it ranged from 1 to $55 \%$, and in two patients with pancreatic steatorrhoea it was 65 and $68 \%$.

The faecal excretion of radio-oleic acid was $1 \%$ or less in six normal subjects, in four patients with pancreatic steatorrhoea it was between 3 and $7 \%$, while in eight patients with steatorrhoea not of pancreatic aetiology it ranged from 8 to $25 \%$.

The results of the estimation of the radioactivity in the urine after the oral administration of radiotriolein and radio-oleic acid were too variable to be of any help in the diagnosis of steatorrhoea.

The value of the radio-oleic-acid test is stressed. It would appear that this test may be more helpful than the radiotriolein test in the diagnosis of steatorrhoea.

In detecting cases of steatorrhoea due to pancreatic failure, the radio-oleic-acid test is of value both when administered alone and when used in conjunction with the radio-triolein test.

We are grateful to the physicians and surgeons of the United Oxford Hospitals for their kindness in allowing us to study their patients ; to Dr. H. T. Howat, of Manchester Royal Infirmary, for permission to study patients under his care ; and to Professor L. J. Witts for his helpful advice and criticism.

\section{REFERENCES}

Balint, J., Pendower, J., and Ramsey, N. W. (1960). Clin. Sci., 19. 321

Baylin, G. J., Sanders, A. P., Isley, J. K., Shingleton, W. W. Hymans, J. C., Johnston, D. H., and Ruffin, J. M. (1955) Proc. Soc. exp. Biol. (N.Y.) 89, 51

Beres, P., Wenger, J., and Kirsner, J. B. (1957). Gastroenterology, 32. 1.

Grossman, M. I., and Jordan, P. H. (1958). Ibid., 34, 892

Hoffman, M. C.'(1953). J. Lab. clin. Med., 41, 521

Malm, J. R., Reemtsma, K., and Barker, H. G. (1956). Proc. Soc. exp. Biol. (N.Y.), 92, 471.

Pimparkar, B. D., Tulsky, E. G., Kalser, M. H., and Bockus, H. L. (1961), Amer. J. Med., 30, 927.

van de Kamer, j. H., Huinink, H. ten B., and Weyers, H. A. (1949) J. biol. Chem.. 177, 347.

van Pandel, E., and Zilversmit, D. B. (1957). Fed. Proc., 16 131.

Walker, W. F., Stewart, W. K., Morgan, H. G., and McKie, J (1960). Brit. med. J., 1, 1403.

\title{
PINEAL ENLARGEMENT, WITH HYPERNATRAEMIA, HYPOKALAEMIC ALKALOSIS, AND THYROTOXICOSIS
}

BY

\author{
A. KENNEDY, M.B., Ch.B. \\ Lecturer in Pathology \\ D. KILSHAW, F.I.M.L.T. \\ Chief Technician
}

N. C. R. W. $\begin{gathered}\text { REID, } \\ \text { Medical Registrar }\end{gathered}$

AND

\section{W. H. TAYLOR, M.A., D.M., M.R.C.P. Chemical Pathologist}

From the Department of Pathology, University of Liverpool; the Royal Infirmary; and the Department of Chemical Pathology, Liverpool

Experimental work in animals suggests that adrenoglomerulotrophin, a hormone controlling the secretion of aldosterone by the adrenal cortex, is elaborated in the pineal gland and neighbouring areas of the brain (Farrell, 1959). The hormone has been tentatively identified as 1-methyl-6-methoxy-1,2,3,4-tetrahydro-2carboline (Farrell and McIsaac, 1961). The association of pineal enlargement with many of the features of primary hyperaldosteronism in the case described below is thus of interest, and it is believed that this is the first case of its kind to be reported.

Methods.-Urinary 17-ketosteroids were determined by the method recommended by the Medical Research Council Committee (1951) and 17-hydroxycorticosteroids by a modification of the method of Moxham and Nabarro (1956). Aldosterone was isolated by the method of Mattox and Lewbart (1959) and its concentra. tion determined in the Aminco-Bowman spectrofluorimeter after coupling with salicyloyl hydrazide (Kilshaw, 1962).

\section{Case History}

A woman aged 58 was admitted to hospital complaining of palpitations of two weeks' duration, of a dry tongue for one week, and of general weakness over the previous four days. Her past health had been good, except that at the age of 46 she was treated for thyrotoxicosis with iodine. There had been no subsequent recurrence of thyrotoxic symptoms.

Inquiry revealed that she had had difficulty in eating solid food because of dryness of the tongue and throat. but that previously her appetite had been excellent. She had felt thirsty, had been drinking more than usual, and had been passing "plenty of urine." She had not been vomiting. She expressed a preference for warm weather, but did not sweat unduly. Two or three formed stools were passed daily. She had probably lost $7 \mathrm{lb}$. $(3.2 \mathrm{~kg}$.) in weight over the previous month. 
On examination the body temperature was $101^{\circ} \mathrm{F}$ $\left(38.3^{\circ}\right.$ C.). Her face was flushed, the mouth and pharynx were reddened, and the tongue was dry, but the skin was not inelastic. There was no objective evidence of loss of weight. The hands and feet were warm and dry. The thyroid gland was not enlarged but bilateral exophthalmos and lid-lag were found; these had been present since her previous attack of thyrotoxicosis. The chest was clear, but the breathing was rapid and shallow. The heart was fibrillating, and the blood-pressure was 180/80. With application of the sphygmomanometer, Trousseau's sign was elicited.

Biochemical Findings (Table 1).- The patient had persistent hypernatraemia and hyperchloraemia with low urinary output of sodium and chloride. There was also hypokalaemia and a raised plasma bicarbonate concentration with good urinary excretion of potassium. The blood urea was slightly raised initially, and rose terminally, although there was no histological evidence of renal damage. The colour of the urine on day 7 suggested that it was moderately well concentrated but unfortunately the specific gravity was not determined.

TABLE I.-Biochemical Findings

\begin{tabular}{|c|c|c|c|c|c|c|c|c|c|}
\hline \multirow{3}{*}{$\begin{array}{c}\text { Day } \\
\text { after } \\
\text { Admis- } \\
\text { sion }\end{array}$} & \multicolumn{2}{|c|}{$\begin{array}{l}\text { Fluid Intake } \\
\text { (ml.) }\end{array}$} & \multirow{3}{*}{$\begin{array}{c}\text { Urin- } \\
\text { ary } \\
\text { Out- } \\
\text { put } \\
\text { (ml.) }\end{array}$} & \multirow{3}{*}{$\begin{array}{l}\text { Hb } \\
(\%)\end{array}$} & \multirow{3}{*}{$\begin{array}{c}\text { Blood } \\
\text { Urea } \\
(\mathrm{mgg} / \\
100 \mathrm{ml} .)\end{array}$} & \multicolumn{4}{|c|}{ Serum } \\
\hline & \multirow[b]{2}{*}{ Oral } & \multirow[b]{2}{*}{ I.V. } & & & & $\mathrm{Na}^{+}$ & $\mathrm{K}^{+}$ & $\mathbf{C l}^{\prime}$ & $\mathrm{HCO}_{\mathrm{s}}{ }^{\prime}$ \\
\hline & & & & & & \multicolumn{4}{|c|}{ mEq'1. } \\
\hline $\begin{array}{r}0 \\
1 \\
2 \\
* 3 \\
4 \\
+5 \\
+6 \\
7\end{array}$ & $\begin{array}{r}970 \\
1,990 \\
1,480 \\
940 \\
945 \\
1,700\end{array}$ & $\begin{array}{l}1,620 \\
1,420\end{array}$ & $\begin{array}{c}570 \\
940 \\
1,110(1) \\
480(3) \\
540(2) \\
430(3)\end{array}$ & 67 & $\begin{array}{r}90 \\
140\end{array}$ & $\begin{array}{l}183 \\
170\end{array}$ & $\begin{array}{l}4 \cdot 1 \\
3 \cdot 9\end{array}$ & $\begin{array}{l}123 \\
117\end{array}$ & 35 \\
\hline
\end{tabular}

* Started 1 g. $\mathrm{KCl}$ b.d

$\dagger \mathrm{KCl}$ given intravenously also.

\$The quantities of oral fluid do not include soups, gravies, and the water content of meals.

Figures in parentheses indicate number of specimens lost by incontinence. Urine Day 7: Contained trace of protein but no glucose or ketone bodies. $\mathrm{Na}^{+}=7.0 \mathrm{mEq} / 1 . \mathrm{K}^{+}=31.8 \mathrm{mEq} / \mathrm{l} . \quad \mathrm{Cl}^{\prime}=6 \cdot 1 \mathrm{mEq} / \mathrm{l} .17$ - $\mathrm{Ket}$ $16 \cdot 0$ mg.'day. 17-Hydroxycorticosteroids $=33 \cdot 2 \mathrm{mg}$./day. Aldosterone $=$ $14.3 \mu \mathrm{g} . / \mathrm{day}$.

Although there were atypical features, treatment for thyrotoxicosis was started with iodine. She was also given digoxin and was encouraged to drink as much as possible. Nystatin mouth washes were prescribed in order to alleviate the oral symptoms.

Her condition improved for a time, the pulse rate slowed, and the extreme dryness of which she had complained subsided. Her temperature gradually fell without antibiotic therapy and was normal on the fourth day after admission and again on the sixth day. Because of the difficulty in swallowing she was given $5 \%$ glucose solution intravenously for a short period on the fifth and sixth days, in addition to her oral intake. In view of the hypokalaemia, oral potassium supplements were started on the third day and intravenous supplements on the fifth day. On the seventh day. she suddenly collapsed, the blood-pressure became unrecordable, her temperature rose to $104^{\circ} \mathrm{F}\left(40^{\circ} \mathrm{C}\right.$.), and she died within two hours.

\section{Necropsy Findings}

Necropsy was performed 12 hours after death. Externally there was no oedema, no evidence of excessive loss of weight, and the distribution of body hair was normal. The lungs, mediastinum, pleural cavities, and abdominal organs were normal. The coronary arteries contained a few plaques of atheroma. There were a few calcified mesenteric lymph nodes. The combined weight of the kidneys was $190 \mathrm{~g}$.; the external surface was smooth and slightly pale, the cut surface showed pallor of the cortex but no other lesion. The uterus and ovaries were within normal limits. The thyroid gland weighed $58 \mathrm{~g}$; the surface was smooth and the enlargement was uniform. The adrenal glands were normal and weighed $4 \mathrm{~g}$. each.

There were no lesions of the brain or of the meninges, but the pineal organ was enlarged (Fig. 1). After fixation in formol saline it weighed $600 \mathrm{mg}$. and measured 13 by 10 by $6 \mathrm{~mm}$. Its cut surface showed no remarkable features: there was a small cyst, a p p r ox i mately $1.5 \mathrm{~mm}$. in diameter, and calcification was slight. Histologically there was no evidence of haemorrhage, tumour, or extensive cystic change. Fibrosis was not marked and calcification

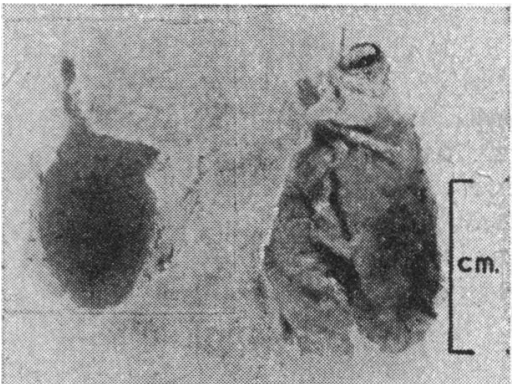

Fig. 1.-Left, pineal gland of normal size. Right, pineal gland from the present case. was normal for a woman aged 58. The organ was moderately cellular (Fig. 2) but the pineocytes themselves showed no unusual features. The nuclei were large and vesicular. , Their mean diameter was $7.4 \mu$ and approximately a fifth of them showed the appearance of nuclear pellets ("kernkugeln"). Mitoses were not seen.

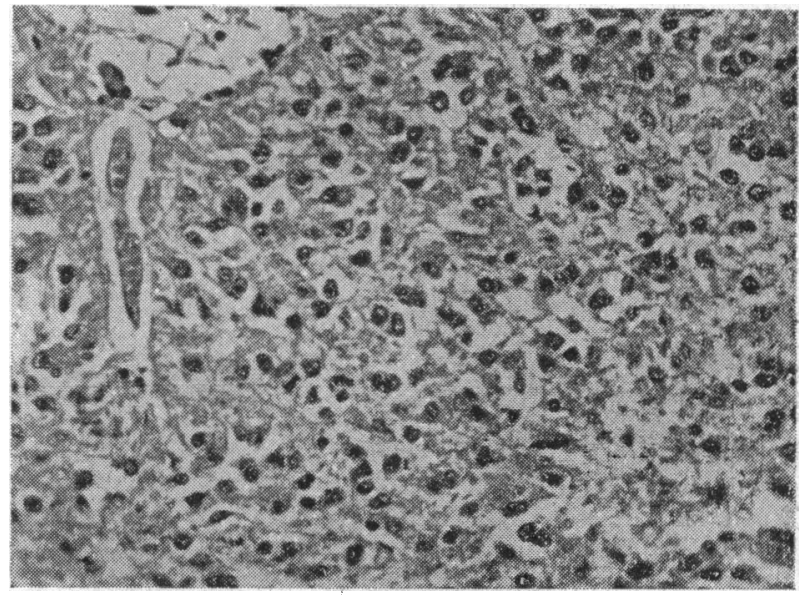

Fig. 2.-Pineal gland. (Haematoxylin and eosin. $\times 235$.)

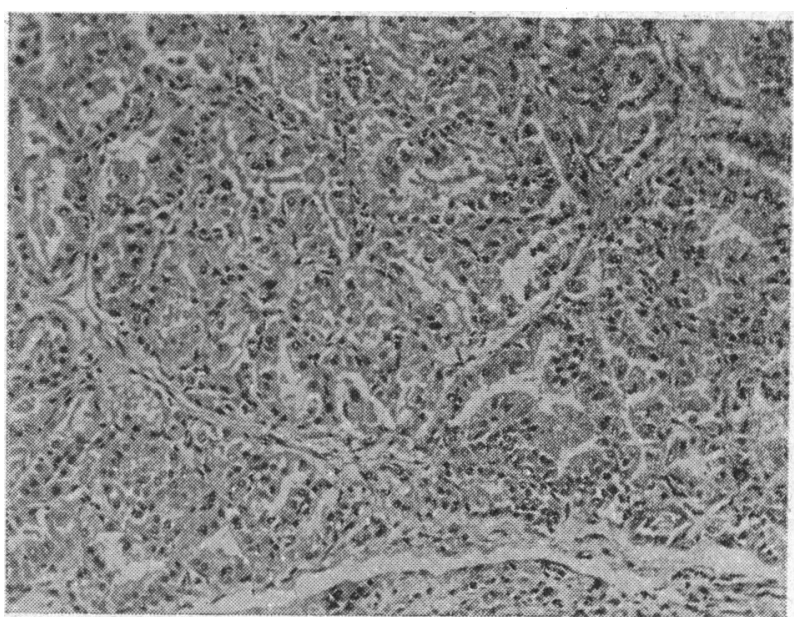

FIG. 3.-Thyroid, showing active epithelium and scanty colloid storage. (Haematoxylin and eosin. $\times 115$.) 
Sections of the adrenals and pituitary showed no abnormalitv. Sections of the thyroid gland showed nodular areas of hyperplasia with little colloid storage (Fig. 3). The appearances were those of thyrotoxicosis. Sections of the kidney showed a bloated, foamy epithelium in the proximal convoluted tubules of the type often seen after the intravenous administration of glucose. There was slight intimal thickening in the intralobular arteries and some general increase in the interstitial tissue. No other histological abnormalities were found.

\section{Discussion}

\section{Pineal Enlargement}

The pineal gland in this patient weighed $600 \mathrm{mg}$. and was approximately three times the normal size. In adults the organ usually weighs between 140 and 200 mg. (Kitay and Altschule. 1954). In a series of 24 pineal organs examined by one of us (A.K.) the mean weight was $200 \mathrm{mg}$. (S.D. 83). These glands were obtained from subjects of a wide age-range and were weighed after fixation in formol saline. Only 10 of the bodies were free of disease. The enlargement of the organ in the present case cannot be accounted for by neoplasia. cystic change, or haemorrhage, but results from hypertrophy and hyperplasia.

Abnormalities of the pineal organ in man may be classified as cystic, hypertrophic and hyperplastic, neoplastic, and calcified. Calcified and cystic glands are relatively common and are not associated with metabolic changes. Neoplastic glands may invade the hypothalamus and cause diabetes insipidus. One case has been described with hypernatraemia and anorexia nervosa (Nicholson et al., 1957). This patient, a girl of 9 years. was in some ways similar to our patient. She presented with fever and anorexia. the serum sodium was $180 \mathrm{mEq} / \mathrm{l}$. and the chloride $150 \mathrm{mEq} / \mathrm{l}$., but the serum potassium was normal. $4.4 \mathrm{mEq} / \mathrm{l}$. Operation revealed a tumour diagnosed histologically as a malignant pinealoma pressing on the optic chiasma.

Reports of pineal hypertrophy and hyperplasia are infrequent. Kitay and Altschule (1954) found 15 cases but mentioned no constant clinical features, nor any association between pineal hypertrophy and either thyrotoxicosis or disturbances of water and electrolyte metabolism. One patient (Bartlett, 1913) was an acromegalic who, in addition to pineal hypertrophy, had a colloid goitre, thymic enlargement, and hyperplasia of the lymph nodes. There was no evidence of thyrotoxicosis but the patient had polyuria during life. It seems probable that the pineal enlargement may have been an expression of the acromegalic syndrome. Rabson and Mendenhall (1956) have described the cases of three siblings with pineal hyperplasia, adrenal cortical hyperplasia, diabetes mellitus, and hirsutism. All died in childhood. None of them showed signs of thyrotoxicosis and no electrolyte studies were reported.

TABle II.-Age and Sex Distribution of 19 Published Cases of

\begin{tabular}{|c|c|c|c|c|}
\hline $\begin{array}{l}\text { Age } \\
\text { in Years }\end{array}$ & Male & Female & $\begin{array}{l}\text { Sex Not } \\
\text { Specified }\end{array}$ & Totals \\
\hline $\begin{array}{c}6-10 \\
11-15 \\
16-20 \\
21-2.5 \\
26-30 \\
80+ \\
\text { Age not given }\end{array}$ & $\begin{array}{l}3 \\
2 \\
2 \\
1 \\
1 \\
1 \\
-\end{array}$ & $\begin{array}{l}\frac{3}{2} \\
\frac{1}{1} \\
\frac{1}{1}\end{array}$ & $\begin{array}{l}\bar{Z} \\
\bar{z}\end{array}$ & $\begin{array}{l}6 \\
2 \\
4 \\
2 \\
1 \\
1 \\
3\end{array}$ \\
\hline Totals & 10 & 7 & 2 & 19 \\
\hline
\end{tabular}

In one, at necropsy, the combined weight of the adrenal glands was $15 \mathrm{~g}$. and the zona glomerulosa was relatively thick. The pineal organ measured 20 by 12 by $6 \mathrm{~mm}$. after formalin fixation. The pineocytes appeared to be normal. The authors suggested that there was a functional familial pineal deficiency with a compensatory hyperplasia.

Table Il shows the age and sex distribution of 19 published cases of pineal hypertrophy. It can be seen that in over half the cases death occurred by the age of 20 years.

\section{Pineal Adrenoglomerulotrophin}

Experimental evidence links the pineal area with the elaboration of adrenoglomerulotrophin. The question therefore arises of whether the enlarged. cellular pineal organ of our patient could have produced the observed clinical and biochemical changes by causing an excessive secretion of aldosterone from the adrenal cortex.

In favour of such a hypothesis are the following facts. (1) The raised plasma sodium level with a low urinary sodium output. (2) The hypokalaemic alkalosis with a normal urinary excretion of potassium. (3) The absence of other causes of this abnormal electrolyte pattern. Thus there was no vomiting, no high intake of sodium, and any mild initial dehydration was corrected during treatment. Certainly the clinically normal state of hydration during the last three days of life was incompatible with the severe dehydration that would have been expected if such a degree of hypernatraemia were due to water deprivation. (4) Latent tetany. (5) The slightly raised urinary excretion of aldosterone. (6) The absence of any lesion at necropsy other than the pineal and thyroid glandular enlargements, and particularly the absence of any adrenal cortical adenoma or of stenosis of the renal arteries and their branches.

Against such a hypothesis are: (1) The fact that the aldosterone output was only slightly raised above the upper normal limit of $12 \mu \mathrm{g} . / 24$ hours: (2) The markedly raised 17-hydroxycorticosteroid excretion as compared with a normal value of $3-13 \mathrm{mg}$. $/ 24$ hours. Experimentally, pineal adrenoglomerulotrophin causes no increased output of cortisol. (3) The absence of hyperplasia of the zona glomerulosa of the adrenals. (4) The fact that when large doses of aldosterone are injected experimentally in man the serum sodium does not rise to the levels found in our patient (August, Nelson, and Thorn, 1958).

Some of these objections lose their force when looked at in a different way. Thus the raised 17-hydroxycorticosteroid excretion may have been related to the patient's generally deteriorating condition. Furthermore about $7 \%$ of the published cases of primary hyperaldosteronism are recorded as having histologically normal adrenal glands : our patient could be regarded as falling within this group and it may be that in some of the previous cases the causative lesion should have been sought in the pineal area. The inability of exogenous aldosterone to produce more than a moderate hypernatraemia in man may well result from the simultaneous inhibition of the central mechanism for producing endogenous aldosterone. so that a new homoeostatic balance is set. If, as seems possible in our patient. the central mechanism is at fault, the rise of serum sodium level would not be subjected to such a restraint, and higher values might be achieved. 
Hypernatraemia with hyponatruria has been described on several occasions in association with cerebral disease (for references see Taylor, 1962). The sites of brain damage are most usually the orbital surface of the frontal lobes, the hypothalamus, and the brain-stem. Such patients resemble ours in sometimes having a severe degree of hypernatraemia but only a moderately raised aldosterone output (Allott, 1957 ; Taylor, 1962). They differ in not showing hypokalaemia or alkalosis. For this reason, and because of the differing sites of brain damage, it is apparent that the pineal area cannot be the only part of the brain concerned with sodium homoeostasis.

Nevertheless the balance of the evidence in our patient would favour a causative association between the pineal enlargement. the biochemical findings, and some of the clinical features.

\section{Pineal and Thyroid Relationship}

Finally, the significance of the enlarged, toxic thyroid gland of our patient must be considered. The palpitations, hypertension, and auricular fibrillation most probably sprang from this source. There is evidence in the rat that potassium iodide given orally causes pineal hyperplasia. Injection of pineal extract on the other hand produced histological changes in the thyroid suggestive of depression of function (Miline and Scepović, 1959). There seems therefore no reason to attribute any of the other clinical or biochemical features of our patient to the thyrotoxicosis.

\section{Summary}

A patient in whom the pineal organ was cellular and enlarged to about three times the normal size exhibited many of the clinical and biochemical features of hyperaldosteronism, but the adrenal glands were histologically normal. The details of the case are compatible with the hypothesis that the pineal area of the brain is the site of production of adrenoglomerulotrophin, a hormone stimulating the adrenal secretion of aldosterone.

We thank Dr. C. A. Clarke, under whose care the patient was admitted; Dr. T. A. Black, in whose laboratory the serum electrolyte concentrations were determined; and $\mathrm{Mr}$. F. Beckwith for preparing the figures.

\section{REFERENCES}

Allott, E. N. (1957). Lancet. 1, 246

August. J. T. Nelson, D. H., and Thorn, G. W. (1958). J. clin. Invest., 37, 1549.

Bartlett, F. K (1913). Arch. intern. Med., 12, 201

Farrell, G. (1959). Endocrinology, 65, 29.

- and Mclsaac, W. M. (1961). Arch. Biochem., 94, 543

Kilsnaw, D. (1962). To be published.

Kitay, J. I., and Altschule, M. D. (1954). The Pineal Gland. Harvard Univ. Press. Cambridge, Mass.

Mattox. V. R., and Lewbart, M. L. (1959). J. clin. Endocr. 19. 1151.

Medical Research Council Committee on Clinical Endocrinology (1951). Lancet. 2, 585.

Miline, R., and Sćepović, M. (1959). Ann. Endocr. (Paris), 20 sil.

Moxham. A., and Naharro, J. D. N. (1956). J. clin. Path., 9. 351.

Nicholson. M. Keitel. H.. Williams, J., Millican, F., Lourie, R S. Lopresti M Stevens. H and Guin, G. H. (1957) Clin Proc. Child. Hosp. (Wash.), 13. 133.

Rabson, S. M., and Mendenhall, E. N. (1956). Amer. J. clin. Path., 26. 283.

Taylor, W. H. (1962). J. clin. Path., 15, 211.

\section{TRICHOPHYTIC GRANULOMA SIMULATING BAZIN'S DISBASE}

BY

\section{F. F. HELLIER, M.D., F.R.C.P.}

Dermatologist, the General Infirmary, Leeds

Deep granulomatous reactions to ordinary dermatophytic fungi are uncommon and may easily be misdiagnosed. Ingram and Brain (1957) state that in exceptional cases ringworm may cause a deep inflammatory reaction with epithelioid and giant cells ; Lewis and Hopper (1948) refer to it as a rare but classic form in which there may be indolent nodules and plaques. This report is prompted by two cases, the first of which remained undiagnosed for five months, when its similarity to the second case suggested the diagnosis of tinea profunda and this was readily confirmed microscopically.

\section{Case 1}

A married woman aged 53 had a 10-year history of smal lumps appearing at the backs of the legs, more marked on the left leg, which had never been clear; sometimes the lesions developed purulent centres. Apart from the skin, her general health was good.

On examination there were clusters of reddish purple nodules mostly posteriorly over the lower half of the lef leg, with a few on the back of the right leg (Fig. 1). They were $0.5-0.75 \mathrm{~cm}$. in diameter and some were associated with hair follicles. A diagnosis of deep folliculitis or superficial Bazin's disease was made. A swab taken from the skin of the leg was sterile. A course of chloramphenicol and chlorhexidine cream was given without benefit and three doses of superficial $x$ ray $(125 \mathrm{r})$ also had no effect. On the supposition that it might be a nodular vasculitis she was given prednisone $5 \mathrm{mg}$. b.d. for three weeks, again without result. At that date the second patient was first seen and diagnosed as a case of trichophytic granuloma and the similarity with this patient was at once recognized.

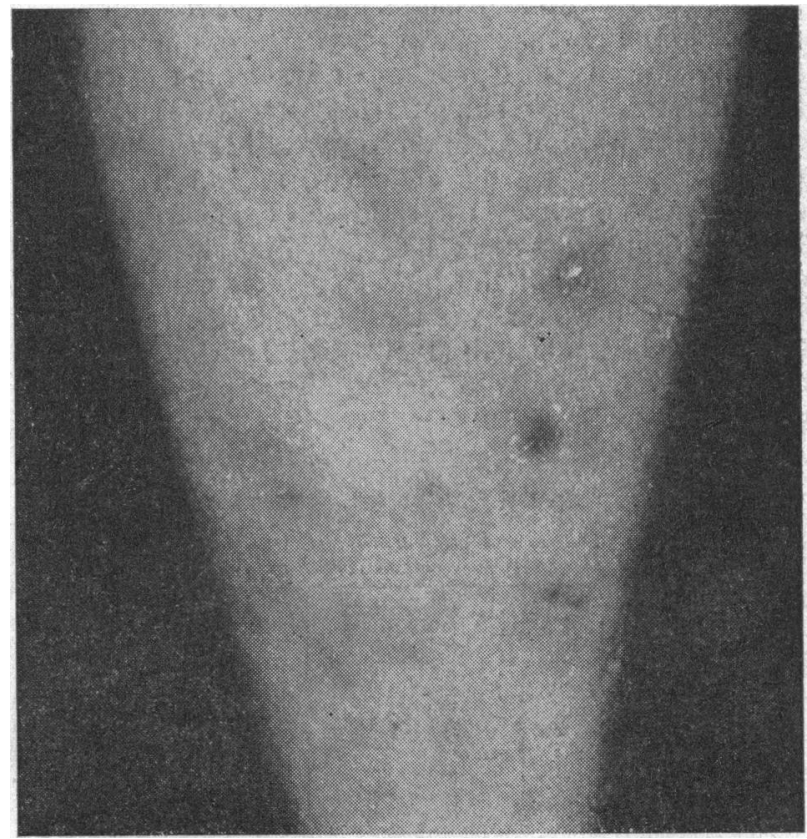

Fig. 1.-Case 1. Nodular lesions caused by a fungus infection suggesting Bazin's disease. 